\title{
Correlation of serum uric acid levels in patients of chronic obstructive pulmonary disease
}

\author{
Anil Sontakke ${ }^{1, *}$, Shashank Kharwade ${ }^{2}$, B. O. Tayade ${ }^{3}$ \\ ${ }^{1}$ Associate Professor, ${ }^{2}$ Senior Resident, ${ }^{3}$ Professor \& HOD, Dept. of Respiratory Medicine, N. K. P. Salve Institute of Medical \\ Sciences \& Research Centre, Nagpur, Maharashtra, India
}

*Corresponding Author:

Email: anilsontakke66@gmail.com

\begin{abstract}
To evaluate serum uric acid level and correlate with the classification of chronic obstructive pulmonary disease (COPD) severity based on post-bronchodilator FEV1 as per Global Initiative for Chronic Obstructive Lung Disease (GOLD) guidelines. It is an institution based cross-sectional study in which 100 patients were included. Patients were screened for COPD. Clinical profile and oxygen saturation were included. Patients were classified according to GOLD guidelines. We found that serum uric acid level was at higher side in patients of severe and very severe stages of COPD compared to mild and moderate stages. Inverse relationship found between FEV1 and serum uric acid level. We concluded that uric acid is a widely available, easy to interpret, low cost biomarker, suggests the possible role in the identification of COPD patients of increased risk for adverse outcomes that may need early intensive management.
\end{abstract}

Keywords: Chronic obstructive pulmonary disease, GOLD guidelines, Spirometry, Serum uric acid.

\section{Introduction}

Pulmonary function declines with long term exposure to smoke. ${ }^{1}$ Impairment of pulmonary function results in decreased oxygen uptake, which results in tissue hypoxia in patients of COPD. Tissue hypoxia induces the degradation of adenosine, which results in release of purine intermediates and end product of purine metabolism like uric acid. ${ }^{2-5}$ In this context, increased levels of uric acid are seen in respiratory disorders, including obstructive sleep apnoea $^{6}$ pulmonary thromboembolism. ${ }^{7}$ There is data regarding the significance of serum uric acid level among patients with COPD. ${ }^{8-12}$

Serum uric acid has been proposed as a marker of impaired oxidative metabolism and an independent prognostic marker in several cardio-vascular disorders such as congestive heart failure ${ }^{13-14}$ pulmonary hypertension ${ }^{15}$ and myocardial infarction and its related complications. ${ }^{16-17}$ There are other biomarkers also which helps in assessing severity of COPD ${ }^{18-19}$ but they are not easily available and are costlier also.

This study was done to assess whether the higher value of serum uric acid corresponds with the severity of COPD as per spirometric classification of COPD according to Global Initiative for Chronic Obstructive Lung Disease (GOLD) guidelines.

\section{Materials and Methods}

This study is a hospital based cross sectional study, conducted in a tertiary care setting from November 2011 to November 2013 after clearance from Institutional Ethics Committee. Study population included current clinical diagnosis of COPD as per GOLD guidelines, current or previous smoker with the history of smoking $>10$ pack year, and ability to compliance with the all study procedure. Patients which were excluded were patients with history or clinical diagnosis of bronchial asthma, congestive heart failure secondary to any cardiac causes, pulmonary hypertension secondary to any heart disease, pulmonary thromboembolism, acute myocardial infarction, pregnant women, breast feeding women, and patients with alcohol and/or drug abuse. 136 Patients were assessed for COPD on the basis of clinical signs and symptoms, smoking history, laboratory tests and spirometery parameters. Out of which 36 patients were excluded from the analysis because they did not meet the GOLD criteria of severity of COPD.

After obtaining written informed consent of all patients, clinical profile consisting age and gender, symptoms, signs, smoking habits, were recorded. We have recorded their oxygen saturation with the help of pulse oxymeter (Schiller multipara with pulse oxymeter). Blood sample was taken from anticubital vein and immediately transferred in the chilled tubes to the Biochemistry lab for serum uric acid analysis. Enzymatic-Colorimetric Trinder. Endpoint method was used for uric acid measurement, and the upper limit of serum uric acid was taken as $7 \mathrm{mg} / \mathrm{dl}$ for male and $6 \mathrm{mg} / \mathrm{dl}$ for female..$^{20-22}$

Spirometric parameters were measured using standard techniques, 23 bronchodilator medications were given in standard dosage protocol (400ug Salbutamol via Meter Dose Inhaler) to the patients and FEV1 was measured after 15-20 minutes. ${ }^{1}$ The highest value of at least three FVC maneuvers was taken by applying within and between-maneuvers acceptability criteria, and repeatability criteria of spirometery. ${ }^{23}$ Patients with FEV1/FVC $<70 \%$ of predicted were identified as with airflow limitation. According to 
GOLD criteria patients with airflow limitation FEV1>80\% were identified as having Mild airflow limitation. And those patient with FEV1\% predicted $<80 \%$ and $>50 \%$ were identified as Moderate airflow limitation. And those patients having FEV1\% >30\% and $<50 \%$ were identified as Severe airflow limitation. While those patients with FEV1\%<30\% predicted and FEV $1 \%<50 \%$ with chronic respiratory failure were classified as having Very severe airflow limitation. ${ }^{1}$

\section{Statistical Analysis}

Clinical and laboratory data all patients is maintained in specified Performa and all the observations and findings were analyzed statistically (SPSS Version 20, 8/9/13). The tests used included Chisquare test, ANOVAs test.

\section{Results}

Out of 100 patients, 77 were males and 23 were females. Dyspnoea was the most common symptom in these patients. Among these COPD patients 21 were non-smoker, and 79 patients were smoker. 47 patients had 10-20 pack years smoking index, 22 patients had 21-30 pack years smoking index, and 10 patients had 31-40 pack years smoking index. Distribution of patients according to spirometry classification of COPD depending upon post bronchodilator FEV1, were as follows, $7 \%$ patients were under the mild stage, 53\% patients were under moderate stage. $27 \%$ patients were under severe stage, $13 \%$ patients were under very severe stage of COPD (Fig. 1).

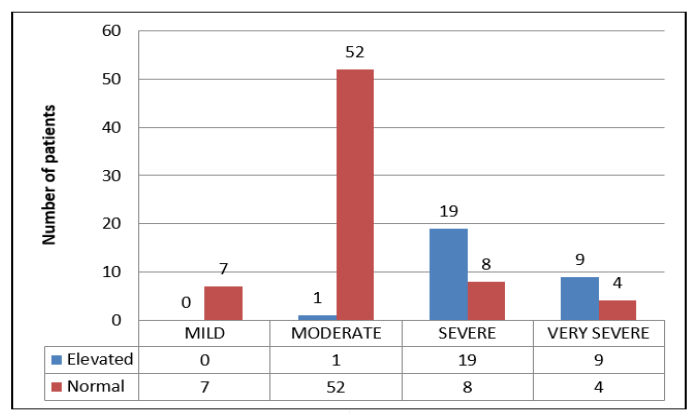

Fig. 1: Association of stages of severity of COPD and Serum Uric Acid

Present study show association of stages of severity of COPD and S.U.A. level, mild stage mean 3.83, moderate stage mean 4.88 severe stage mean 6.86 and very severe stage 6.89 (Table 1 ).

Table 1: Stages of severity of COPD and Serum Uric Acid level

\begin{tabular}{|l|l|l|l|}
\hline Stage & Percentage & Mean & SD \\
\hline Mild & $7 \%$ & 3.83 & 0.586 \\
\hline Moderate & $53 \%$ & 4.88 & 0.978 \\
\hline Severe & $27 \%$ & 6.86 & 1.118 \\
\hline Very Severe & $13 \%$ & 6.89 & 1.739 \\
\hline
\end{tabular}

Maximum number of patients with elevated serum uric acid level were present in severe and very severe stage of COPD (Chi square $=54.44, p<0.01)$. There was no significant independent association between smoking history and serum uric acid level in patients of COPD (Chi square+2.47, p>0.01) (Fig. 2).

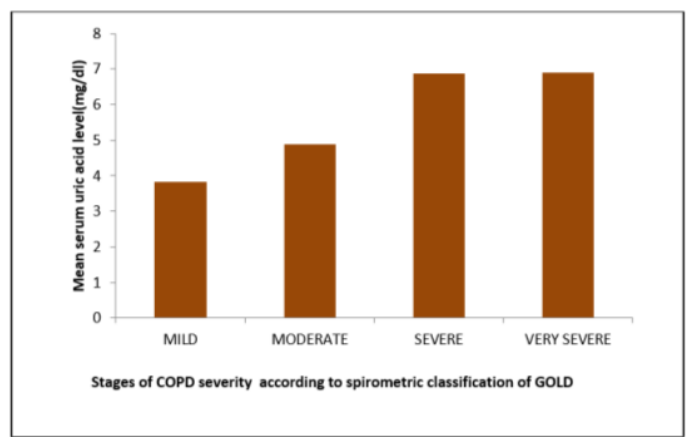

Fig. 2: Serum Uric Acid Level in different stages of spirometery classification of COPD severity

Analysis of variance was carried out which was statistically significant which implies that serum uric acid level is in higher side in patients of severe and very severe stage of COPD compare to mild and moderate grades of COPD. There was inverse relationship between post bronchodilator FEV1 and serum uric acid level (Person correlation coefficient value is -0683 and p<0.01) (Fig. 3).

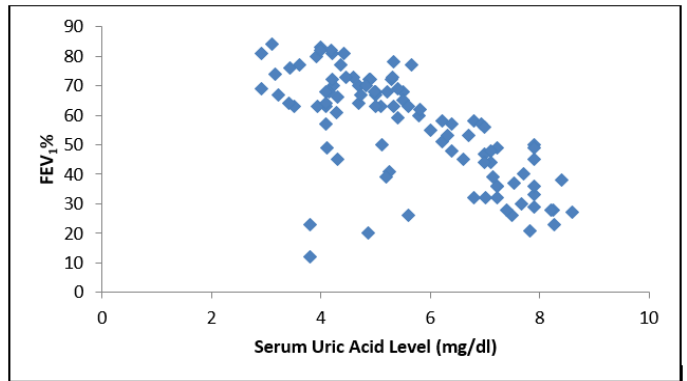

Fig. 3: Correlation of serum uric acid level and post bronchodilator FEV1\%

There was propionate increase in serum uric acid levels in smokers as compared to nonsmokers (Fig. 4).

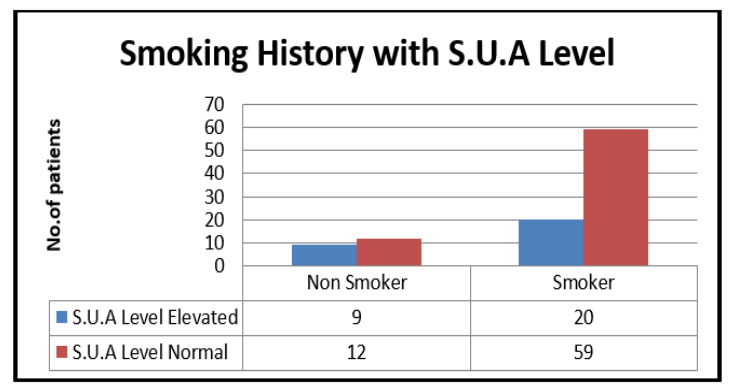

Fig. 4: Association of Smoking History with Serum Uric Acid level 
There was significant inverse correlation between oxygen saturation and serum uric acid level (Pearson Correlation coefficient value is -0.820 and $\mathrm{p}<0.01$ ) (Fig. 5).

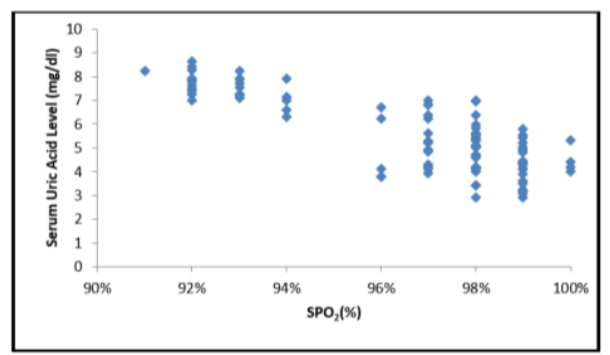

Fig. 5: Relationship between serum uric acid level oxygen saturation
Analysis of variance was carried out which was statistically significant, which implies that serum uric acid level was in higher range in patients of severe and very severe stages of COPD compared to mild and moderate stages of COPD (Table 2).

Table 2: ANOVA (Analysis of variance) of serum uric acid level in different stages of COPD severity

\begin{tabular}{|l|l|l|l|l|l|l|}
\hline Trait & $\begin{array}{l}\text { Sum of } \\
\text { Squares }\end{array}$ & Df & $\begin{array}{l}\text { Mean } \\
\text { Square }\end{array}$ & F & Sig. & Fcrist \\
\cline { 1 - 5 } $\begin{array}{l}\text { Between Groups } \\
\text { (Combined) }\end{array}$ & 113.893 & 3 & 37.964 & 30.215 & 0.000 & 3.0241 \\
\hline Within Groups & 120.620 & 96 & 1.256 & & & \\
\hline Total & 234.513 & 99 & & & & \\
\hline
\end{tabular}

\section{Discussion}

In the present study, we demonstrated that there is inverse relationship between oxygen saturation and serum uric acid level. Pulmonary hypoxia promotes purine catabolism, leading to increased production of uric acid. ${ }^{5}$ Adenosine is a pulmonary vasodilator and it may modulate the pulmonary vasopressor response to acute alveolar hypoxia. ${ }^{2,25}$ James O. Woolliscroft et $\mathrm{al}^{3}$ demonstrated that tissue hypoxia may contribute to the sequence of event by leading to the depletion of adenosine triphosphate (ATP) and activation of purine nucleotide degradation to uric acid. Meteos Anton F et $\mathrm{al}^{24}$ found that in patients with COPD and severe hypoxemia there was marked increase in the degradation of adenine nucleotide by reduced ATP synthesis caused by oxygen deprivation, hence there was increased level of purine metabolites like hypoxanthine, xanthine, uric acid and total purines. Present study data is suggestive of tissue hypoxia is a most important cause of elevated serum uric acid level in COPD patients.

COPD is characterized by systemic inflammation and elevated SUA levels have been associated with increased levels of inflammatory markers. Leonardo $\mathrm{M}$ Fabbri $^{26}$ emphasized the use of the term chronic systemic inflammatory syndrome and diagnosis of chronic systemic inflammatory syndrome can be made by the presence of at least three of the following components: (I) Age older than 40 years (II) Smoking for more than 10 pack years, (III) Symptoms and abnormal lung function compatible with COPD, (IV) Chronic heart failure, (V) Metabolic syndrome, (VI) Increased C-reactive protein. In another study
Carmelinda Reuffiero et $\mathrm{al}^{27}$ studied relationship between baseline uric acid and changes in uric acid circulating levels with C-reactive protein and interleunkin-6 hey found that increased serum uric acid was closely associated with systemic inflammation. Present study data suggested that systemic inflammation occurs in patients of COPD and increase level of serum uric acid is associated with systemic inflammation.

In present study no significant independent association found between smoking history and serum uric acid level in patient of COPD Nicks ME et $\mathrm{al}^{28}$ in their study described that lower plasma UA was associated with more severe COPD and, suggested that antioxidant balance was impaired in smokers. Konstantions Bartziokas et $\mathrm{a}^{10}$ demonstrated that there was no independent relationship between uric acid level and history of smoking in pack years. But in other studies it was demonstrated that uric acid is a biomarker of zanthine oxidase activity, it is an important source of oxygen species, ${ }^{29}$ Yoko Shibata et $\mathrm{al}^{9}$ in their study described that chronic smoking is one of the possible cause of elevated serum uric acid level in patients of COPD. This data suggested that relationship between uric acid level and smoking history needs further evaluation.

In the evaluation of serum uric acid levels we need to take into account that this metabolite is the endproduct of purine degradation that increases in a very sensitive but nonspecific way in several forms of tissue damage and inflammation, all being very dynamic process in COPD patients. ${ }^{16-17}$ Uric acid levels are influenced by several factors including cardiovascular 
disease, excessive intake of foods containing purine bases, alcohol consumption renal dysfunction and genetic disorders of purine metabolism, such as LeschNyhan syndrome drugs like thiazide diuretics. ${ }^{30}$ There are also genetic influences in the way COPD patients react to inflammation. ${ }^{19}$ In addition demo-graphic and clinical factors, such as gender, BMI, smoking index, BP and serum glucose levels, are known to be associated with serum levels of uric acid consideration of these factors is required when assessing the relationship between pulmonary function and uric acid levels.

\section{Conclusion}

This study we have shown that are significant inverse correlation between spirometric FEV1\% predicated and serum uric acid level, serum uric acid level is at higher range in patients of severe and very severe stage of COPD compared to mild and rapidly available, easy to interpret, cost effective biomarker, suggests the possible role for serum UA in the identification of COPD patients of increased risk for adverse outcomes that need early intensive management.

\section{Limitation of Study}

1. Limited sample size

2. Area of coverage was limited

Future research is required to further delineate and characterize the prevalence, frequency, and serum uric acid levels in patients with chronic obstructive pulmonary disease. Future prospect study should be developed in cooperation large sample size and mass study with appropriate methodology to capture the frequency and prevalence of serum uric acid levels in patients with chronic obstructive pulmonary disease.

\section{References}

1. Global initiative for chronic Obstructive Lung Disease. Global strategy for the diagnosis, management and prevention of chronic obstructive pulmonary disease (Internet). (Updated 2010: cited 2011 June 15) Available from: http://www.goldcopd.org/.

2. Mentzer RM Jr, Rubio R, Berne RM. Release of adenosine by hypoxic canine lung tissue and its possible role in pulmonary circulation. Am J Physiol 1975;229(6):1625-31.

3. Woolliscroft JO, Colfer H, Fox IH. Hyperuicaemia in acute illness: A poor prognostic sign Am J Med 1982;72(1):58-62.

4. Fox JH. Metabolic basis for disorders of purine nucleotide degradation. Metabolism 1981; 30(6):616634.

5. Elsayed NM, Nakshima JM, Postelethwait EM. Measurement of uric acid as a marker of oxygen tension in the lung. Arch Bio-Chem Biophys 1993:302(1):228-32.

6. Saito H, Nishimura M, Shibuya E. Tissue hypoxia in sleep apnea syndrome assessed by uric acid and adenosine. Chest 2002;122(5):1686-94.

7. Shimizu Y, Nagaya N, Satosh T. Serum uric acid level increases in proportion to the severity pulmonary thromboembolism. Cire J 2002;66(6):571-5.
8. Garcia-Pachon E, Padilla-Navas I, Shum C. Serum uric acid to creatinine ratio in patients with chronic obstructive pulmonary disease. Lung 2002;185(1):21-24.

9. Aida Y, Shibata Y, Osaka D, Abe S, Inoue S, Fukuzaki K, Toka et al. The relationship between serum uric acid and spirometric values in participant in a health check: The Takahata study. Int J Med Sci 2011;8(6):470-8.

10. Bartziokas K, Papaioannou AI, Loukides S, Papadopoulos A, Haniotou A, Papiris S, et al. Serum uric acid as a predictor of mortality and future exacerbations of COPD. Eur Respir J 2014 Jan;43(1):43-53.

11. Inocencio H. Lopez. Serum uric acid levels among patients with chronic obstructive pulmonary disease. Chest 124 (4_Meeting Abstract) 2003: 168S. Available from: http://journal.publications.chestnet.org/article.aspx?articleid $=1091101$.

12. Sato N, Kurashima K, Ubukata M. Prognostic significance of serum uric acid in patients with chronic obstructive pulmonary disease receiving home oxygen therapy. Nihon Kokyuki Gakkai Zasshi 2003;41(2):74-80.

13. Amin A, Yakilian F, Makki M. Serum uric acid level correlate with filling pressure in systolic heart failure. Congest Heart Fall 2011;17(2):80-4.

14. Pascual-Figal DA, Hurtado-Martinez JA, Redondo B, Antolinos M, Ruiperez JA, Valides M. Hyperuricaemia and long-term outcome after hospital discharge in acute heart failure patients. Eur J Heart Fail 2007;9(5):518-24.

15. Voelkel MA, Wynne KM, Badesch DB. Hyperuricemia in severe pulmonary hypertension. Chest 2000;117(1):19-24.

16. Holme I, Aastveit AH, Hammar N. Uric acid and risk of myocardial infarction, smoke and congestive heart failure in 417,734 men and women in the apolipoprotein mortality risk study (AMORIS). J Intern Med 2009;266(6):558-70.

17. NadkarMY, Hain VI. Serum uric acid in acute myocardial infarction. J Assoc Physicians India 2008;56:759-62.

18. Gan WQ, Man SF, Senthilselvan A, Sin DD. Association between chronic obstructive pulmonary disease and systemic inflammation: A systemic review and a metaanalysis. Thorax 2004;59(7):574-80.

19. Yanbaeva DG, Dentener MA, Creutzbarg EC, Wouters EF. Systemic inflammation in COPD: is genetic susceptibility a key factor? COPD 2003;3(1);51-61.

20. Fossati P, Prencipe L, BertiG. Use of 3, 5-dichloro2hydroxybenesulfonic acid/4-aminophenazone chromogenic system in direct enzymic assay of uric acid in serum and urine. Clin Chem 1980;26(2);227-31.

21. Lal SS, Sukla Y, Singh A, Andriyas EA and Lall AM. Hyperuricemia, High Serum Urea and Hypoproteinemia are the Risk factor for Diabetes. Asian Journal of Medical Sciences 2009;1(2):33-4.

22. Conen D, Wietlishbach V, Bovet P. Prevalence of hyperuricemia and relation of serum uric acid with cardiovascular risk factors in a developing country. BMC Public Health 2004;4:9.

23. Miller MR, Hankinson J, Brusaco V, Burgos F, Casaburi R, Coates A, et al. Standardization of spirometery. Eur Respir J 2005;26(2):319-38.

24. Mateos Anton F, Garcial Puig J, Gomez Fernandez P, Ramos Hernandez T, Lopez Jimemez M. Degradation of purine nucleotides in patients with chronic obstruction to airflow. Med Clin (Barc) 1989;92(9):328-30.

25. Ryu JH, Krowka MJ, Pellikka PA. Pulmonary hypertension in patients with interstitial lung diseases. Mayo Clin Proc 2007;82(3):342-50.

26. Fabbri LM, Rabe KF. From COPD to chronic systemic inflammatory syndrome? Lancet 2007;370 (9589):797-9. 
27. Ruggiero C, Cherubini A, Ble A, Bos AJ, Maggio M, Dixit VD. Uric acid and inflammatory markers. Eur Heart J 2006;27(10):1174-81.

28. Nicks ME, O'Brein MM, Bowler RP. Plasma antioxidants are associated with impaired lung function COPD exacerbation in smokers. COPD 2011;8(4):264-9.

29. McCord JM, Roy RS, Schaffer SW. Free radicals and myocardial ischemia. The role of xanthine oxidase. Adv Myocardial 1985;5:183-9.

30. Choi H, Liu S, Curhan G. Intake of purine-rich foods, protein, and dairy products and relationship to serum levels of uric acid: The third national health and nutrition examination survey. Arthrits Rheum 2005;52(1):283-9. 